\title{
Effects of DNA topoisomerase Il $\alpha$ splice variants on acquired drug resistance
}

\author{
Terry S. Elton ${ }^{1}$, Hatice Gulcin Ozer², Jack C. Yalowich ${ }^{1}$ \\ 'Division of Pharmaceutics and Pharmacology, College of Pharmacy, The Ohio State University, Columbus, OH 43210, USA. \\ 2Department of Biomedical Informatics, College of Medicine, The Ohio State University, Columbus, OH 43210, USA.
}

Correspondence to: Prof. Jack C. Yalowich, Division of Pharmaceutics and Pharmacology, College of Pharmacy, The Ohio State University, 500 West 12th Avenue, Columbus, OH 43210, USA. E-mail: yalowich.1@osu.edu; Prof. Terry S. Elton, Division of Pharmaceutics and Pharmacology, College of Pharmacy, The Ohio State University, 500 West 12th Avenue, Columbus, OH 43210, USA. E-mail: elton.8@osu.edu

How to cite this article: Elton TS, Ozer HG, Yalowich JC. Effects of DNA topoisomerase Il $\alpha$ splice variants on acquired drug resistance. Cancer Drug Resist2020;3:161-70. http://dx.doi.org/10.20517/cdr.2019.117

Received: 23 Dec 2019 First Decision: 21 Jan 2020 Revised: 29 Jan 2020 Accepted: 12 Feb 2020 Available online: 27 Feb 2020

Science Editors: William Henry Gmeiner, Robert C.A.M. van Waardenburg Copy Editor: Jing-Wen Zhang Production Editor: Tian Zhang

\begin{abstract}
DNA topoisomerase Il $\alpha(170 \mathrm{kDa}$, TOP2 $\alpha / 170)$ induces transient DNA double-strand breaks in proliferating cells to resolve DNA topological entanglements during chromosome condensation, replication, and segregation. Therefore, TOP $2 \alpha / 170$ is a prominent target for anticancer drugs whose clinical efficacy is often compromised due to chemoresistance. Although many resistance mechanisms have been defined, acquired resistance of human cancer cell lines to TOP2 $\alpha$ interfacial inhibitors/poisons is frequently associated with a reduction of Top $2 \alpha / 170$ expression levels. Recent studies by our laboratory, in conjunction with earlier findings by other investigators, support the hypothesis that a major mechanism of acquired resistance to TOP $2 \alpha$-targeted drugs is due to alternative RNA processing/splicing. Specifically, several TOP $2 \alpha$ mRNA splice variants have been reported which retain introns and are translated into truncated TOP2 $\alpha$ isoforms lacking nuclear localization sequences and subsequent dysregulated nuclear-cytoplasmic disposition. In addition, intron retention can lead to truncated isoforms that lack both nuclear localization sequences and the active site tyrosine (Tyr805) necessary for forming enzyme-DNA covalent complexes and inducing DNA damage in the presence of TOP $2 \alpha$-targeted drugs. Ultimately, these truncated TOP $2 \alpha$ isoforms result in decreased drug activity against TOP $2 \alpha$ in the nucleus and manifest drug resistance. Therefore, the complete characterization of the mechanism(s) regulating the alternative RNA processing of TOP2 $\alpha$ pre-mRNA may result in new strategies to circumvent acquired drug resistance. Additionally, novel TOP $2 \alpha$ splice variants and truncated TOP2 $\alpha$ isoforms may be useful as biomarkers for drug resistance, prognosis, and/or direct future TOP2 $\alpha$-targeted therapies.
\end{abstract}

Keywords: DNA topoisomerase Il $\alpha$, chemoresistance, alternative splicing, intron retention, topoisomerase II $\alpha$ interfacial inhibitors/poisons

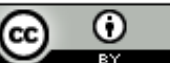

(C) The Author(s) 2020. Open Access This article is licensed under a Creative Commons Attribution 4.0 International License (https://creativecommons.org/licenses/by/4.0/), which permits unrestricted use, sharing, adaptation, distribution and reproduction in any medium or format, for any purpose, even commercially, as long as you give appropriate credit to the original author(s) and the source, provide a link to the Creative Commons license, and indicate if changes were made.

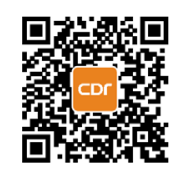




\section{INTRODUCTION}

The human DNA topoisomerase II $\alpha(170 \mathrm{kDa}$, TOP2 $\alpha / 170)$ enzyme functions as a homodimer with the active site Tyr805 residues in each subunit initiating reversible transesterification reactions to generate TOP $2 \alpha / 170-D N A$ covalent cleavage complexes ${ }^{[1-4]}$. These transient TOP $2 \alpha / 170$ mediated double-strand DNA breaks are essential in proliferating cells so that entanglements which occur during DNA repair, recombination, replication, transcription, and segregation can be resolved by allowing the passage of double-stranded DNA segments through these openings ${ }^{[1-4]}$. Given that TOP $2 \alpha / 170$ enzymatic activity is necessary for cell survival, TOP $2 \alpha$ interfacial inhibitors/poisons (e.g., etoposide, mitoxantrone, doxorubicin, daunorubicin, and analogs) are widely exploited as anticancer drugs ${ }^{[5-8]}$. These therapeutic agents exert their cytotoxic effects by impeding the reversal of the TOP $2 \alpha / 170-D N A$ covalent cleavage complexes, which subsequently leads to the accumulation of DNA breaks and ultimately cell death ${ }^{[5-8]}$.

TOP2 $\alpha$ poisons are commonly used as chemotherapeutic agents in adults and pediatric patients to treat a wide variety solid tumors, leukemias, and lymphomas ${ }^{[9-11]}$. For example, cisplatin/etoposide is first-line treatment for small cell lung cancer ${ }^{[12,13]}$; doxorubicin and epirubicin are used in combination with other drugs as a preoperative/adjuvant therapy regimen for the treatment of breast cancer ${ }^{[1,15]}$; and daunorubicin and mitoxantrone are used in treating acute myeloid leukemia $(\mathrm{AML})^{[16,17]}$.

Although TOP $2 \alpha$ poisons are extensively utilized, the efficacy of these important drugs is often compromised due to acquired chemoresistance ${ }^{[18-21]}$. While many chemoresistant mechanisms have been defined ${ }^{[22,23]}$, acquired resistance to $\mathrm{TOP}_{2} \alpha$ poisons is frequently associated with decreased $\mathrm{TOP} 2 \alpha / 170$ expression levels or altered sub-cellular localization of TOP $2 \alpha / 170$ given that the cytotoxic activity of these drugs is dependent upon the formation of TOP $2 \alpha / 170-D N A$ covalent cleavage complexes ${ }^{[18-21]}$. In this review, we focus on the molecular mechanisms underlying the decreased TOP $2 \alpha / 170$ expression levels in chemoresistant cell lines due to alternative RNA processing.

\section{ALTERNATIVE SPLICING}

Alternative splicing is a process by which a single pre-mRNA is matured into multiple mRNA isoforms that can contribute to transcriptomic and proteomic diversity ${ }^{[24]}$. RNA-seq data predict that over $95 \%$ of human genes generate at least two alternative spliced mRNA isoforms ${ }^{[24]}$. Several modes of alternative splicing of a pre-mRNA have been described: exon skipping, differential inclusion of an exon, alternative splice ( 5 ' splice or $3^{\prime}$ splice) site selection, and intron retention ${ }^{[24]}$. Intron-retaining mRNA transcripts are susceptible to nuclear intron detention ${ }^{[25]}$, or nonsense mediated decay ${ }^{[26,27]}$, and as a consequence gene expression is reduced at the post-transcriptional level. However, some intron-retaining mRNA transcripts leave the nucleus and undergo translation to produce new protein isoforms with novel functions ${ }^{[28-31]}$. Such seems to be the case with a number of documented TOP $2 \alpha$ mRNA splice variants, which retain introns, are translated into truncated $\mathrm{TOP} 2 \alpha$ isoforms, and play a role in mediating $\mathrm{TOP} 2 \alpha$ poison chemoresistance in various cell lines ${ }^{[32-36]}$.

\section{THE HUMAN TOP $2 \alpha$ GENE AND TOP2 $\alpha / 170$ PROTEIN EXPRESSION}

The human TOP $2 \alpha$ gene comprises 35 exons, spans 30 kb (NCBI Reference Sequence: NG_027678.2) [Figure $1 \mathrm{~A}]^{[37]}$, and has been mapped to chromosome $17 \mathrm{q} 21-22^{[38]}$. A 5695 nucleotide (nt) mRNA (NCBI Reference Sequence: NM_001067.4) [Figure 1A-i] is matured from the TOP2 $\alpha$ gene and the open reading frame encodes a protein comprising 1531 amino acids (aa), with a calculated molecular weight of $174,386 \mathrm{Da}$ (i.e., TOP2 $\alpha / 170$ ) [Figure $1 \mathrm{~B}-\mathrm{i}]^{[37]}$. TOP2 $\alpha$ exons 1-12 encode the ATP binding domain ${ }^{[37]}$ near the N-terminus and acts as a gate (ATP gate) [Figure $1 \mathrm{~B}-\mathrm{i}$ ] when two TOP $2 \alpha / 170$ subunits homodimerize ${ }^{[39,40]}$. When the ATP gate is open, one DNA duplex (designated the G- or "gate"-segment) is loaded into the enzyme cavity and a 
i.

\begin{tabular}{|l|l|l|l|l|r|}
\hline Exon 1-/ Exon 18 & Exon 19 & Exon 20 & Exon 21-/ Exon 33 & E-34 & E-35 (AAA) \\
3'
\end{tabular}

TOP2 $\alpha$ gene (exons 1-35) wild-type splicing $\mathrm{E}-1 \sim \mathrm{E}-18 \sim \mathrm{E}-19 \sim \mathrm{E}-20 \sim \mathrm{E}-21 \sim \mathrm{E} \sim \mathrm{E}-33 \sim 2$

Retained Intron 33 TOP2 $\alpha$ mRNA $(4,550 \mathrm{nt})$
\begin{tabular}{|l|l|l|l|l|l|} 
Exon 1- & Exon 18 & Exon 19 & Exon 20 & Exon $21-/$ Exon 33 & I-33 \\
(AAA) $)_{n}$
\end{tabular}

\alternative splicing

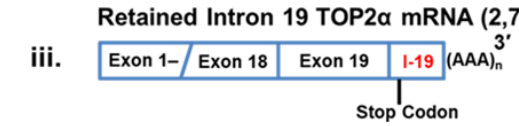

B

Wild-Type - TOP2 $\alpha$ 1,531 amino acids: TOP2 $\alpha / 170$

i.

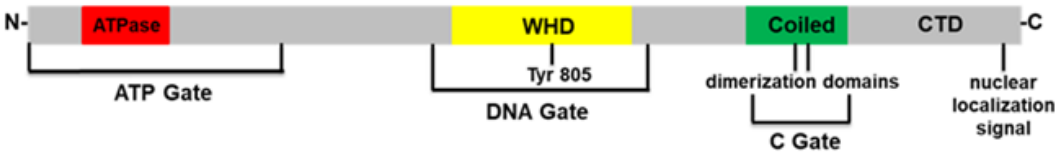

Intron 33 Retention - TOP2 $\alpha 1436$ amino acids: TOP2 $\alpha / 160$

ii.

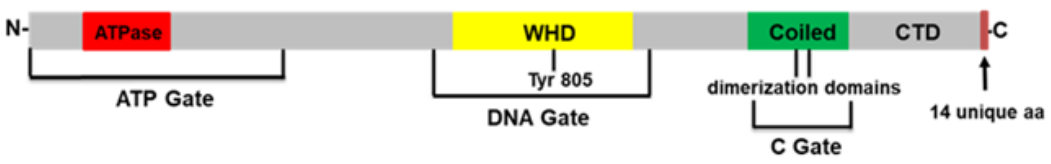

Intron 19 retention - TOP2 $\alpha 786$ amino acids: TOP2 $2 \alpha / 90$

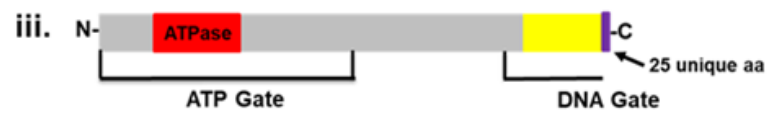

C

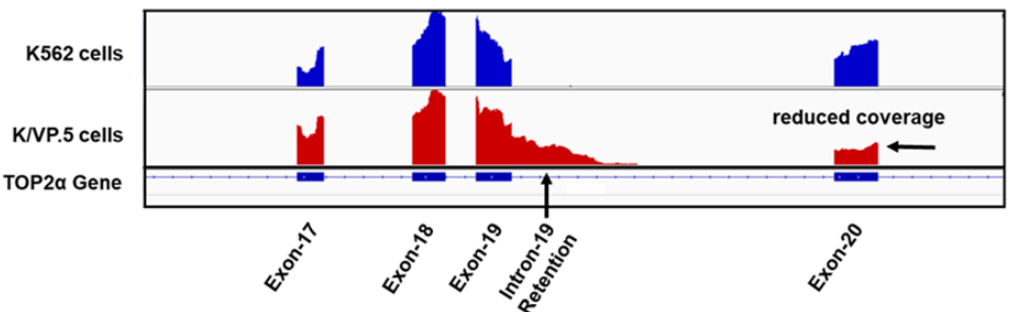

Figure 1. Schematic representation of the human TOP $2 \alpha$ gene, TOP $2 \alpha$ mRNAs, TOP $2 \alpha$ protein, and visualization of RNA-seq results. A: the human TOP2 $\alpha$ gene is comprised of 35 exons. At least three mature mRNA transcripts (i-iii) can be transcribed from the human TOP $2 \alpha$ gene. Two of these mRNAs harbor retained and processed introns; B: the three TOP $2 \alpha$ mRNAs encode three distinct TOP $2 \alpha$ protein isoforms. Depicted are the ATP gate, which harbors the ATPase domain; the DNA gate, which includes the winged-helix domain and harbors the active site tyrosine, Tyr805; the $C$ gate, which comprises the coiled-coil region (coiled domain) and the characterized dimerization sequences, DD1053-1069 and DD1121-1143 ${ }^{[41-45]}$; and the C-terminal domain, which contains the defined nuclear localization signal NLS1454-1497 ${ }^{[46,47]}$; C: visualization of retained intron 19 of TOP2 $\alpha$ RNA-seq genome coverage tracks showing the intron 19 retention event in K/VP.5 cells. RNA-seq raw reads from K562 and K/VP.5 RNA samples were mapped to the human reference genome GRCh38 using Hierarchical Indexing for Spliced Alignment for Transcripts v.2.1.0 ${ }^{[48]}$ and visualized using the Integrative Genomics Viewer $^{[49]}$. Reduced coverage denoted for Exon 20 indicates fewer full length TOP $2 \alpha / 170$ reads in K/VP.5 cells. (A, B) Images adapted in part from Figures 1A, B published originally in the Journal of Pharmacology and Experimental Therapeutics; Kanagasabai et al. ${ }^{[35]}$, 2017. TOP2 $\alpha$ : topoisomerase Il $\alpha$; WHD: winged-helix domain; CTD: C-terminal domain; DD: dimerization domains

transient double-strand DNA break is generated (i.e., TOP $2 \alpha / 170-\mathrm{DNA}$ covalent cleavage complex ${ }^{[39,40]}$ within the DNA gate [Figure $1 \mathrm{~B}-\mathrm{i}$ ], which is encoded by TOP2 $\alpha$ exons $13-27^{[37]}$. The transesterification reaction, which is mediated by the active site Tyr805 residue on each monomer, is encoded by exon $20^{[37]}$. Subsequently, the "transfer"-segment (T-segment) is captured within the ATP gate upon ATP binding and is transported 
through the DNA gate ${ }^{[39,40]}$. This intact DNA duplex then exits from the open C gate ${ }^{[39,40]}$, which comprises the coiled-coil region (coiled domain) and the C-terminal domain from each monomer encoded by TOP $2 \alpha$ exons $28-35^{[37]}$ [Figure 1B-i]. After T-segment strand passage and ATP hydrolysis, the G-segment doublestrand DNA break is resealed and free Tyr805 residues present in each $\mathrm{TOP} 2 \alpha / 170$ subunit are regenerated. Finally, the ATP gate is reopened, and this processive enzyme is reset for another round of catalytic activity ${ }^{[39,40]}$. Given the complexity of this enzyme's reaction cycle, truncated TOP2 $\alpha$ isoforms, translated as a result of alternative RNA splicing, may exhibit atypical TOP2 $\alpha$ functionality and response to targeted agents.

\section{TOP2 $\alpha / 160$ (INTRON 33 RETENTION) AND CHEMORESISTANCE}

Several acquired and innate resistant models have been reported, which involve intron retention due to alternative RNA processing of TOP $2 \alpha \mathrm{mRNA}^{[32-36]}$. Harker et al. ${ }^{[50]}$ generated a mitoxantrone resistant human AML (HL-60) cell line designated HL-60/MX2 (35-fold resistant), by stepwise drug exposure from 1.7 to $170 \mathrm{nM}$. HL-60/MX2 cells were found to be cross-resistant to a number of TOP2 $\alpha$ poisons including etoposide, amsacrine, teniposide, daunorubicin, and doxorubicin ${ }^{[50]}$. Compared to parental HL-60 cells, HL$60 / \mathrm{MX} 2$ cells contained reduced TOP $2 \alpha / 170$ protein levels and expressed a novel truncated TOP $2 \alpha$ isoform migrating at $\sim 160 \mathrm{kDa}$ (TOP2 $\alpha / 160$ ) that localized predominantly to the cytoplasm ${ }^{[51]}$. Interestingly, TOP $2 \alpha / 160$ (1436 aa and a calculated molecular weight of $164,052 \mathrm{Da}$ ) is the translation product of a TOP $2 \alpha$ mRNA (4550 nt) that harbors exons $1-33$ and retains a processed intron 33 (125 nt) that contains an in-frame stop codon and a consensus poly(A) site [Figure $1 \mathrm{~A}-\mathrm{ii}]^{[32]}$. As a result of intron 33 retention and processing, TOP $2 \alpha / 160$ is missing the C-terminal 108 aa present in TOP $2 \alpha / 170$ (1531 aa), which are replaced by 14 unique aa encoded by translation of the exon 33/intron 33 "read-through" [Figure $1 \mathrm{~B}-\mathrm{ii}]^{[32]}$. Importantly, TOP $2 \alpha / 160$ is missing the well-characterized nuclear localization signal (NLS) NLS1454$1497^{[46,47]}$ [Figure 1B-ii]. This isoform is also missing a "chromatin tether" sequence, which interacts with histone tails and anchors TOP $2 \alpha / 170$ to nucleosomes ${ }^{[52]}$. These deletions may account for the accumulation of TOP $2 \alpha / 160$ in the cytoplasm ${ }^{[32]}$.

Similarly, Feldhoff et al. ${ }^{[53]}$ generated a resistant $\mathrm{H} 209$ small cell lung cancer cell line, designated H209/V6 (22-fold resistant), by stepwise selection in etoposide (from 0.2 to $6 \mu \mathrm{M}$ ). These investigators demonstrated that, compared to parental $\mathrm{H} 209$ cells expressing TOP2 $\alpha / 170, \mathrm{H} 209 / \mathrm{V} 6$ cells only expressed a TOP2 $\alpha / 160$ isoform ${ }^{[53]}$. Additionally, it was shown by immunocytochemistry and cytoplasm/nuclear fractionation studies that TOP $2 \alpha / 160$ was primarily localized in the cytoplasm ${ }^{[54]}$. Yu et al.$^{[33]}$ subsequently characterized a TOP $2 \alpha$ mRNA splice variant (7090 nt) expressed in the etoposide resistant H209/V6 cell line that harbored exons 1-33, the entire intron 33, and included exons 34 and 35 [see Figure 1A for orientation]. Although this mRNA is much longer than the $4550 \mathrm{nt}$ transcript from HL60/MX2 cells ${ }^{[32]}$, it is still translated into the same TOP2 $\alpha / 160(1436 \mathrm{aa}, 164,052 \mathrm{Da})$ isoform described above by Harker et al. ${ }^{[32]}$ [Figure 1A-ii] due to the in-frame stop codon present in retained intron 33, loss of the canonical NLS, and consequent aberrant localization in the cytoplasm ${ }^{[3,53,54]}$.

Mo and Beck $^{[34]}$ characterized TOP $2 \alpha$ mRNA splice variants in TOP2 $\alpha$ poison sensitive T-lineage tumor cell lines (e.g., CEM, Jurkat, and H9). One of four TOP2 $\alpha$ mRNA splice variants characterized in CEM cells was identical to the transcript that was described above by Harker et al. ${ }^{[32]}$ with exons 1-33, followed by a retained and processed intron 33 (4550 nt), and again encoded the identical TOP2 $\alpha / 160$ (1436 aa, 164,052 Da). This truncated TOP $2 \alpha$ isoform and others generated from intron retention in T-cell lines were lacking the canonical $\mathrm{NLS}$ and all were detected in cytoplasmic extracts ${ }^{[34]}$. Interestingly, normal T-cells contained only TOP $2 \alpha / 170$, prompting these investigators to suggest that splice variants of TOP $2 \alpha$ play a role in leukemogenesis, although no further investigations to explore this possibility have been reported.

Together, these previous reports suggest that intron retention can play a role in generation of truncated $\mathrm{TOP} 2 \alpha$ isoforms secondary to alternative RNA processing. The production of truncated TOP $2 \alpha$ isoforms can be determinants of drug resistance and/or play a role tumor cell biology not yet characterized. 
$\underline{\text { TOP2 } \alpha / 90 / 170 \mathrm{~N}-\text { term Ab }}$

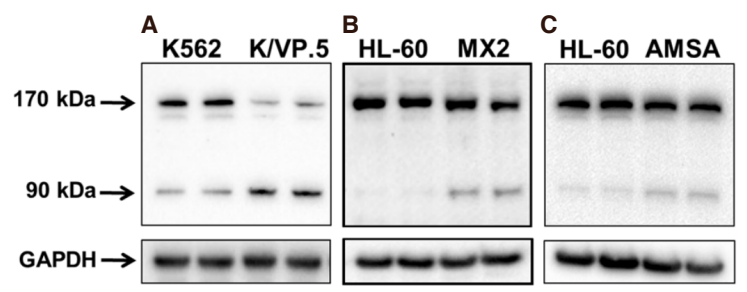

Figure 2. A novel human TOP $2 \alpha / 90$ isoform is overexpressed in acquired resistance to TOP $2 \alpha$-targeted drugs etoposide, mitoxantrone, and amsacrine. A: TOP2 $\alpha$ immunoassay utilizing K562 and K/VP. $5^{[35,36,55,56]}$ cell lysates; B: TOP2 $\alpha$ immunoassay utilizing HL-60 and HL$60 / \mathrm{MX}^{[32,50,51]}$ cell lysates; C: TOP2 $\alpha$ immunoassay utilizing HL-60 and HL-60/AMSA ${ }^{[57]}$ cell lysates. The immunoblots were probed with an antibody specific for the $\mathrm{N}$-terminal portion of TOP $2 \alpha / 170$ (i.e., amino acids $14-27$, denoted $\mathrm{N}$-terminal $\mathrm{Ab}$ ). (A) Image is from Figure 2A published originally in the Journal of Pharmacology and Experimental Therapeutics; Kanagasabai et al. ${ }^{[35]}, 2017$. TOP2 $\alpha$ : topoisomerase $1 / \alpha$

\section{TOP $2 \alpha / 90$ (INTRON 19 RETENTION) AND CHEMORESISTANCE}

Our laboratory has also investigated the molecular mechanisms which lead to decreased TOP $2 \alpha / 170$ expression levels in acquired chemoresistance. Resistant human leukemia K562 cells were generated by intermittent then continuous treatment with $0.5 \mu \mathrm{M}$ etoposide followed by limiting dilution to isolate and then characterize a clonal K/VP.5 cell line ${ }^{[55]}$. Compared to parental K562 cells, the K/VP.5 subline was 30fold resistant to etoposide and cross-resistant to teniposide, mitoxantrone, doxorubicin, and amsacrine ${ }^{[56]}$. This multi-drug resistance was not mediated by overexpression of $\mathrm{ABCB} 1^{[56]}$. K/VP. 5 cells exhibited reduced TOP $2 \alpha / 170$ mRNA (by Northern blot analysis) with no change in transcription compared to K562 cells ${ }^{[55]}$. In addition, using an antibody generated from the C-terminal $70 \mathrm{kDa}$ of TOP2 $\alpha$, immunoassays of cells lysates demonstrated reduced TOP2 $\alpha / 170$ protein levels in K/VP.5 compared to K562 cells $^{[55,56]}$.

Surprisingly, additional immunoblotting experiments using a N-terminal specific TOP2 $\alpha / 170$ antibody (generated against amino acids 14-27) revealed the presence of two major TOP $2 \alpha$ proteins, the expected wild-type TOP $2 \alpha / 170$ isoform and a novel $90 \mathrm{kDa}$ isoform, TOP $2 \alpha / 90$ [Figure $2 \mathrm{~A}]^{[35,36]}$. Compared to parental K562 cells, the expression level of TOP $2 \alpha / 170$ was attenuated as expected but TOP $2 \alpha / 90$ was increased in K/ VP. 5 cells [Figure $2 \mathrm{~A}]^{[35,36]}$. Immunoassays utilizing cell lysates from two additional TOP $2 \alpha$-poison resistant cell lines, HL-60/MX2 (mitoxantrone-resistant) ${ }^{[32]}$ and HL-60/AMSA (amsacrine-resistant) ${ }^{[57]}$, also demonstrated greater TOP2 $\alpha / 90$ protein levels compared to parental HL-60 cells [Figure $2 \mathrm{~B}$ and C].

Using 3'-rapid amplification of cDNA ends (3'-RACE), followed by PCR and sequencing, analyses revealed that TOP $2 \alpha / 90$ mRNA (2762 nt) shares the first 19 exons with the TOP $2 \alpha / 170$ transcript. However, the TOP $2 \alpha / 90$ mRNA retains a processed intron 19 (380 nt) that harbors an in-frame stop codon, and two consensus poly(A) sites [Figure $1 \mathrm{~A}-\mathrm{iii}]^{[35]}$. TOP $2 \alpha / 90$ mRNA lacks the published TOP $2 \alpha / 170$ transcript sequences from exon 20 to 35, and harbors a novel 3'-untranslated region (302 nt) [Figure 1A-iii] ${ }^{[35]}$. TOP $2 \alpha / 90$ mRNA intron 19 retention was validated by mapping RNA-seq raw reads [Figure $1 \mathrm{C}$ ].

The TOP $2 \alpha / 90$ mRNA encodes a truncated TOP $2 \alpha$ protein isoform of 786 aa with a calculated molecular weight of $90,076 \mathrm{Da}$, which is approximately one half the size of the wild-type TOP $2 \alpha / 170$ protein (i.e., 1531 aa, $174,385 \mathrm{Da}$ ) [Figure $1 \mathrm{~B}]^{[35,36]}$. Although TOP2 $\alpha / 90$ is identical to TOP $2 \alpha / 170$ for the first $761 \mathrm{aa}$, this protein is missing the C-terminal 770 aa present in TOP $2 \alpha / 170$, which are replaced with 25 unique amino acids encoded by the exon 19/intron 19 "read-through" [Figure 1B-iii]. As a result of intron 19 retention, the truncated TOP2 $\alpha / 90$ isoform does not harbor an active site tyrosine (Tyr805), which is present in the DNA gate domain [Figure $1 \mathrm{~B}]$ and is required for wild-type TOP2 $\alpha / 170$ to generate double-strand DNA breaks ${ }^{[1-4]}$. Finally, TOP $2 \alpha / 90$ is also missing two characterized dimerization domains (DD) (i.e., 1053-1069 aa and $1121-1143 \mathrm{aa})^{[41-44]}$ and NLS $1454-1497^{[46,47]}$ present in wild-type TOP $2 \alpha / 170$ [Figure $1 \mathrm{~B}$ ]. 


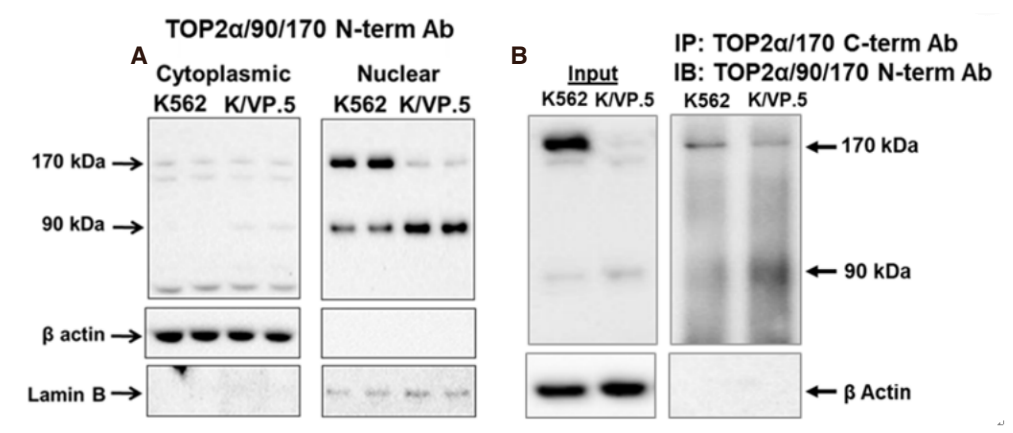

Figure 3. TOP $2 \alpha / 90$ can be detected in both nuclear and cytoplasmic extracts and heterodimerizes with TOP $2 \alpha / 170$. A: TOP $2 \alpha$ immunoassay using K562 and K/VP.5 cytoplasmic and nuclear lysates ${ }^{[36]}$. Immunoblots were probed with TOP2 $\alpha / 90 / 170$ and $\beta$-actin antibodies; B: immunoprecipitation experiments were performed using K562 and K/VP.5 whole cell lysates. The precipitated immune complexes were released in SDS-PAGE sample buffer, subjected to SDS-PAGE, and immunoblotted, using the indicated antibodies. Input immunoblots are also shown for each experiment and $\beta$-actin antibody loading controls. (A, B) Images are reproduced/adapted from Figures 2B and 3D, respectively, published originally in Molecular Pharmacology; Kanagasabai et al. ${ }^{[36]}, 2018$. TOP2 $\alpha$ : topoisomerase Il $\alpha$; SDS-PAGE: sodium dodecyl sulfate-polyacrylamide gel electrophoresis

It was hypothesized that, similar to the Top $2 \alpha / 160$ truncated isoforms described above ${ }^{[32-34]}$, TOP $2 \alpha / 90$ would be predominantly located in the cytoplasm since this isoform does not contain NLS 1454-1497 [Figure 1B]. Surprisingly, however, immunoassays using fractionated cytoplasmic and nuclear extracts [Figure 3A] and immunofluorescence experiments (not shown) demonstrated that TOP2 $\alpha / 90$ was predominantly detected in the nucleus of K562 and K/VP.5 cells ${ }^{[36]}$. Currently, it is not known how $\mathrm{TOP} 2 \alpha / 90$ is transported into the nucleus; a plausible speculation is that TOP $2 \alpha / 90$ enters nuclei by a "piggy-back" mechanism ${ }^{[58]}$ (e.g., heterodimerization) with TOP $2 \alpha / 170$, since the full-length isoform harbors functional NLS. In addition, TOP $2 \alpha / 90$ may contain operative NLS sites. Mirski et al. ${ }^{[47]}$ found three bipartite NLS sequences in the first $743 \mathrm{TOP} 2 \alpha$ aa but these were not functional. A short nonclassical IK-NLS motif ${ }^{[58]}$ (KVSKNK) in TOP2 $\alpha / 90$ is currently under study for functionality.

Although TOP $2 \alpha / 90$ does not harbor the DD essential for TOP2a/170:TOP2a/170 homodimerization [Figure $1 \mathrm{~B}]^{[41-45]}$, co-immunoprecipitation experiments demonstrated that endogenous TOP $2 \alpha / 90$ and TOP $2 \alpha / 170$ proteins form heterodimers in both K562 and K/VP.5 cells [Figure 3B] ${ }^{[36]}$. While these results were unexpected, several studies have shown that human $\mathrm{N}$-terminal $\mathrm{TOP} 2 \alpha$ fragments, which encompass just the ATPase domain (i.e., aa 1-435), dimerize in vitro under the appropriate conditions ${ }^{[59-61]}$. Importantly, Bjergbaek et al. ${ }^{[45]}$ established that, if the C-terminal primary DD present in TOP $2 \alpha / 170$ were deleted, dimerization could still occur in the presence of DNA and an ATP analog.

Given that TOP $2 \alpha / 90$ lacks the active site tyrosine residue (Tyr805) required to form TOP2 $\alpha / 170-\mathrm{DNA}$ covalent complexes [Figure $1 \mathrm{~B}$-iii], and is capable of heterodimerization with TOP2 $\alpha / 170$ [Figure $3 \mathrm{~B}$ ], it was posited that this isoform may be dominant-negative relative to drug-induced DNA damage and cytotoxicity. Consistent with this hypothesis, forced overexpression of TOP $2 \alpha / 90$ in K562 cells (which express low levels of Top $2 \alpha / 90$ ) decreased etoposide-induced DNA damage and cytotoxicity in K562 cells [Figure 4$]^{[35,36]}$. Conversely, etoposide-induced DNA strand breaks were increased in K/VP.5 cells subsequent to siRNA knockdown of elevated levels of TOP2 $\alpha / 90$ [Figure 4$]^{[35,36]}$.

Initial qPCR evaluation of paired AML patient samples (pre-treatment and relapse) indicated an increase in the ratio of expression of TOP $2 \alpha / 90$ mRNA compared to TOP $2 \alpha / 170$ after relapse ${ }^{[36]}$. In addition, the ratio of TOP $2 \alpha / 90$ to TOP $2 \alpha / 170$ protein was increased after treatment relapse ${ }^{[36]}$. To date, in four of six AML patients, there was a statistically significant increase in the TOP $2 \alpha / 90$ to $\mathrm{TOP} 2 \alpha / 170$ ratio after relapse 


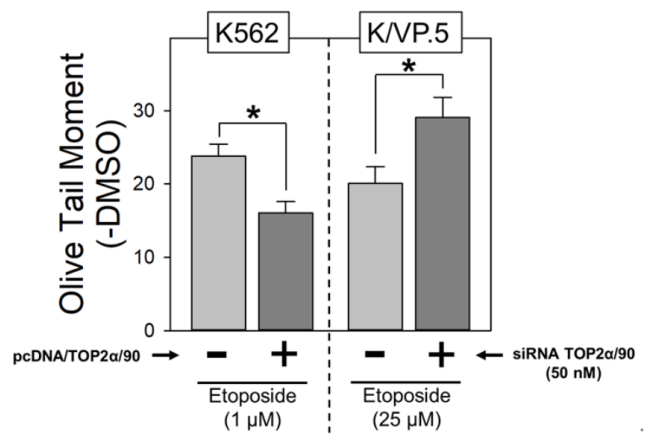

Figure 4. TOP $2 \alpha / 90$ exhibits dominant-negative properties. A: etoposide $(1 \mu \mathrm{M})$-induced DNA damage in empty vector and pcDNA/ TOP2 $\alpha / 90$-transfected K562 cells was determined by neutral comet assays (assessing DNA double-strand breaks) after a 1-h incubation and subtraction of DMSO vehicle controls. The results shown are the mean \pm SEM for three experiments run on separate days. ${ }^{\star} P<$ 0.025, comparing pcDNA/TOP2 $\alpha / 90$-transfected to empty vector-transfected K562 cells; B: etoposide (25 $\mu$ M)-induced DNA damage in negative control or TOP $2 \alpha / 90$-specific Silencer Select Custom Designed TOP $2 \alpha / 90$ siRNAs ( $50 \mathrm{nM}$ ) transfected K/VP. 5 cells was determined as above. The results shown are the mean \pm SEM for five to six experiments run on separate days. ${ }^{\star} P<0.025$, comparing TOP $2 \alpha / 90$ siRNA-transfected to negative control siRNA transfected K/VP. 5 cells. For all experimental conditions in each experiment, greater than 100 cells were evaluated by OpenComet software. (A, B) Images are adapted from Figures 4B (left) and Figure 5B (right) respectively, originally published in Molecular Pharmacology; Kanagasabai et al. ${ }^{[36]}, 2018$. TOP2 $\alpha$ : topoisomerase Il $\alpha$; pcDNA: plasmid cloning DNA; DMSO: dimethyl sulfoxide; siRNA: small interfering RNA

(unpublished data). These results suggest a role for TOP $2 \alpha / 90$ in resistance/relapse in patients and may lead to forward development of TOP $2 \alpha / 90$ as a biomarker for development of drug resistance.

Overall, the studies described above strongly suggest that TOP $2 \alpha / 90: T O P 2 \alpha / 170$ heterodimers produce dominant-negative effects by reducing the number of TOP $2 \alpha / 170-\mathrm{DNA}$ covalent cleavage complexes that can be "trapped" by etoposide treatment. In turn, drug-induced DNA damage and cytotoxic action of etoposide are decreased. Therefore, we conclude that enhanced expression of TOP $2 \alpha / 90$ in K/VP. 5 cells is a determinant of chemoresistance through a dominant-negative effect related to heterodimerization with TOP $2 \alpha / 170$. Given that TOP $2 \alpha / 90$ mRNA is expressed in normal human tissues ${ }^{[36]}$, the formation of TOP $2 \alpha / 90: \mathrm{TOP}_{2} \alpha / 170$ heterodimers may also play a role to protect against xenobiotics targeting TOP $2 \alpha / 170$ or to "fine tune" levels of cleavage complexes.

Although this review focuses on variant pre-mRNA TOP $2 \alpha / 170$ splicing in drug resistance, drugs that target type II topoisomerases also impact the $180 \mathrm{kDa}$ isoform TOP2 $\beta / 180$, a separate gene product and not a splice variant ${ }^{[62]}$. Unlike TOP $2 \alpha / 170$, TOP $2 \beta / 180$ levels are maintained throughout the cell cycle ${ }^{[62]}$. This isoform is important for transcriptional control and may play a role in drug-induced malignancies ${ }^{[63,64]}$. It is interesting to note that HL60/MX2 cells with intron 33 retention in TOP $2 \alpha / 170$ have completely lost expression of TOP $2 / \beta$ protein ${ }^{[32]}$. In addition, K/VP.5 cells with intron 19 retention in TOP $2 \alpha / 170$ do not seem to have similar alternative RNA processing of TOP $2 \beta$ based on $\mathrm{qPCR}$ evaluations across exon-exon junctions ${ }^{[35]}$. The paucity of information regarding potential splicing alterations in TOP2 $\beta$ in acquired drug resistance is a gap in knowledge which affords an opportunity for future investigations.

\section{CONCLUSION}

Previous reports ${ }^{[32-34]}$, in conjunction with our newer studies ${ }^{[35,36]}$, support the conclusion that alternative TOP $2 \alpha$ RNA processing is a determinant of acquired drug resistance and suggests that C-terminal truncated TOP $2 \alpha$ isoforms may have additional biologic functions. Therefore, future studies are warranted to characterize the mechanisms by which alternative spliced TOP $2 \alpha$ mRNAs are generated with the hope that these studies will lead to new strategies to circumvent acquired drug resistance. Further investigations may also lead to the development of tumor cell/biopsy evaluation of TOP $2 \alpha$ isoforms as biomarkers for drug resistance, prognosis, and/or guide TOP2 $\alpha$-targeted therapies. 


\section{DECLARATIONS}

\section{Authors' contributions}

Made substantial contributions to conception, design, performed data analysis, and interpretation: Elton TS, Ozer HG, Yalowich JC

\section{Availability of data and materials}

Not applicable.

\section{Financial support and sponsorship}

This work was supported by the National Institutes of Health National Cancer Institute (Grant R01

CA226906-01A1).

\section{Conflicts of interest}

All authors declared that there are no conflicts of interest.

\section{Ethical approval and consent to participate}

Not applicable.

\section{Consent for publication}

Not applicable.

\section{Copyright}

(C) The Author(s) 2020.

\section{REFERENCES}

1. Deweese JE, Osheroff N. The DNA cleavage reaction of topoisomerase II: wolf in sheep's clothing. Nucleic Acids Res 2009;37:738-48.

2. Vos SM, Tretter EM, Schmidt BH, Berger JM. All tangled up: how cells direct, manage and exploit topoisomerase function. Nat Rev Mol Cell Biol 2011;12:827-41.

3. Chen SH, Chan NL, Hsieh TS. New mechanistic and functional insights into DNA topoisomerases. Annu Rev Biochem 2013;82:139-70.

4. Pommier Y, Sun Y, Huang SN, Nitiss JL. Roles of eukaryotic topoisomerases in transcription, replication and genomic stability. Nat Rev Mol Cell Biol 2016;17:703-21.

5. Nitiss JL. Targeting DNA topoisomerase II in cancer chemotherapy. Nat Rev Cancer 2009;9:338-50.

6. Pommier Y, Marchand C. Interfacial inhibitors: targeting macromolecular complexes. Nat Rev Drug Discov 2011;11:25-36.

7. Pommier Y. Drugging topoisomerases: lessons and challenges. ACS Chem Biol 2013;8:82-95.

8. Delgado JL, Hsieh CM, Chan NL, Hiasa H. Topoisomerases as anticancer targets. Biochem J 2018;475:373-98.

9. Economides MP, McCue D, Borthakur G, Pemmaraju N. Topoisomerase II inhibitors in AML: past, present, and future. Expert Opin Pharmacother 2019;20:1637-44.

10. Edwardson DW, Narendrula R, Chewchuk S, Mispel-Beyer K, Mapletoft JPJ, et al. Role of drug metabolism in the cytotoxicity and clinical efficacy of anthracyclines. Curr Drug Metab 2015;16:412-26.

11. Shanbhag S, Ambinder RF. Hodgkin lymphoma: a review and update on recent progress. CA Cancer J Clin 2018;68:116-32.

12. National Comprehensive Cancer Network. NCCN Clinical Practice Guidelines in Oncology: Small Cell Lung Cancer (Version 1.2020). Available from: https://www.nccn.org/professionals/physician_gls/pdf/sclc.pdf [Last accessed on 19 Feb 2020]

13. Zhao H, Ren D, Liu H, Chen J. Comparison and discussion of the treatment guidelines for small cell lung cancer. Thorac Cancer 2018;9:769-74.

14. Greene J, Hennessy B. The role of anthracyclines in the treatment of early breast cancer. J Oncol Pharm Pract 2015;21:201-12.

15. Blum JL, Flynn PJ, Yothers G, Asmar L, Geyer CE Jr, et al. Anthracyclines in early breast cancer: the ABC Trials-USOR 06-090, NSABP B-46-I/USOR 07132, and NSABP B-49 (NRG Oncology). J Clin Oncol 2017;35:2647-55.

16. Owattanapanich W, Owattanapanich N, Kungwankiattichai S, Ungprasert P, Kuchutrakool T. Efficacy and toxicity of idarubicin versus high-dose daunorubicin for induction chemotherapy in adult acute myeloid leukemia: a systematic review and meta-analysis. Clin Lymphoma Myeloma Leuk 2018;18:814-21.e3.

17. National Comprehensive Cancer Network. NCCN Clinical Practice Guidelines in Oncology: Acute Myeloid Leukemia (Version 2.2020). Available from: https://www.nccn.org/professionals/physician_gls/pdf/aml.pdf [Last accessed on 19 Feb 2020]

18. Burgess DJ, Doles J, Zender L, Xue W, Ma B, et al. Topoisomerase levels determine chemotherapy response in vitro and in vivo. Proc Natl Acad Sci U S A 2008;105:9053-58.

19. Pilati P, Nitti D, Mocellin S. Cancer resistance to type II topoisomerase inhibitors. Curr Med Chem 2012;19:3900-06. 
20. Ganapathi RN, Ganapathi MK. Mechanisms regulating resistance to inhibitors of topoisomerase II. Front Pharmacol 2013;4:89.

21. Capelôa T, Benyahia Z, Zampieri LX, Blackman MCNM, Sonveaux P. Metabolic and non-metabolic pathways that control cancer resistance to anthracyclines. Semin Cell Dev Biol 2020;98:181-91.

22. Zahreddine H, Borden KL. Mechanisms and insights into drug resistance in cancer. Front Pharmacol 2013;4:28.

23. Cree IA, Charlton P. Molecular chess? Hallmarks of anti-cancer drug resistance. BMC Cancer 2017;17:10.

24. Lee Y, Rio DC. Mechanisms and regulation of alternative pre-mRNA splicing. Annu Rev Biochem 2015;84:291-323.

25. Boutz PL, Bhutkar A, Sharp PA. Detained introns are a novel, widespread class of post-transcriptionally spliced introns. Genes Dev 2015;29:63-80.

26. Wong JJ, Au AY, Ritchie W, Rasko JE. Intron retention in mRNA: no longer nonsense: known and putative roles of intron retention in normal and disease biology. Bioessays 2015;38:41-9.

27. Kurosaki T, Maquat LE. Nonsense-mediated mRNA decay in humans at a glance. J Cell Sci 2016;129:461-7.

28. Li Y, Bor YC, Fitzgerald MP, Lee KS, Rekosh D, et al. An NXF1 mRNA with a retained intron is expressed in hippocampal and neocortical neurons and is translated into a protein that functions as an Nxfl cofactor. Mol Biol Cell 2016;27:3903-12.

29. Uzor S, Zorzou P, Bowler E, Porazinski S, Wilson I, et al. Autoregulation of the human splice factor kinase CLK1 through exon skipping and intron retention. Gene 2018;670:46-54.

30. Shoubridge C, Jackson M, Grinton B, Berkovic SF, Scheffer IE, et al. Splice variant in ARX leading to loss of C-terminal region in a boy with intellectual disability and infantile onset developmental and epileptic encephalopathy. Am J Med Genet A 2019;179:1483-90.

31. Wang C, Buolamwini JK. A novel RNA variant of human concentrative nucleoside transporter 1 (hCNT1) that is a potential cancer biomarker. Exp Hematol Oncol 2019;8:18.

32. Harker WG, Slade DL, Parr RL, Holguin MH. Selective use of an alternative stop codon and polyadenylation signal within intron sequences leads to a truncated topoisomerase II alpha messenger RNA and protein in human HL-60 leukemia cells selected for resistance to mitoxantrone. Cancer Res 1995;55:4962-71

33. Yu Q, Mirski SE, Sparks KE, Cole SP. Two COOH-terminal truncated cytoplasmic forms of topoisomerase II alpha in a VP-16selected lung cancer cell line result from partial gene deletion and alternative splicing. Biochemistry 1997;36:5868-77.

34. Mo YY, Beck WT. Heterogeneous expression of DNA topoisomerase II alpha isoforms in tumor cell lines. Oncol Res 1997;9:193-204.

35. Kanagasabai R, Serdar L, Karmahapatra S, Kientz CA, Ellis J, et al. Alternative RNA processing of topoisomerase iialpha in etoposide-resistant human leukemia K562 cells: intron retention results in a novel c-terminal truncated 90-kDa isoform. J Pharmacol Exp Ther 2017;360:152-63.

36. Kanagasabai R, Karmahapatra S, Kientz CA, Yu Y, Hernandez VA, et al. The novel C-terminal truncated 90-kDa isoform of topoisomerase IIalpha (TOP2alpha/90) is a determinant of etoposide resistance in K562 leukemia cells via heterodimerization with the TOP2alpha/170 isoform. Mol Pharmacol 2018;93:515-25.

37. Lang AJ, Mirski SE, Cummings HJ, Yu Q, Gerlach JH, et al. Structural organization of the human TOP2A and TOP2B genes. Gene 1998;221:255-66.

38. Tsai-Pflugfelder M, Liu LF, Liu AA, Tewey KM, Whang-Peng J, et al. Cloning and sequencing of cDNA encoding human DNA topoisomerase II and localization of the gene to chromosome region 17q21-22. Proc Natl Acad Sci U S A 1988;85:7177-81.

39. Dong KC, Berger JM. Structural basis for gate-DNA recognition and bending by type IIA topoisomerases. Nature 2007;450:1201-5.

40. Wendorff TJ, Schmidt BH, Heslop P, Austin CA, Berger JM. The structure of DNA-bound human topoisomerase II a: conformational mechanisms for coordinating inter-subunit interactions with DNA cleavage. J Mol Biol 2012;424:109-24.

41. Frère V, Sourgen F, Monnot M, Troalen F, Fermandjian S. A peptide fragment of human DNA topoisomerase II alpha forms a stable coiled-coil structure in solution. J Biol Chem 1995;270:17502-07.

42. Berger JM, Gamblin SJ, Harrison SC, Wang JC. Structure and mechanism of DNA topoisomerase II. Nature 1996;379:225-22.

43. Frère-Gallois V, Krebs D, Scala D, Troalen F, Fermandjian S. Peptide fragments of DNA topoisomerase II with helix-forming and coiled-coil-forming properties act as inhibitors of the enzyme. Eur J Biochem 1997;249:142-8.

44. Kroll DJ. Homologous and heterologous protein-protein interactions of human DNA topoisomerase II alpha. Arch Biochem Biophys 1997;345:175-84.

45. Bjergbaek L, Jensen S, Westergaard $\mathrm{O}$, Andersen $\mathrm{AH}$. Using a biochemical approach to identify the primary dimerization regions in human DNA topoisomerase II alpha. J Biol Chem 1999;274:26529-36.

46. Mirski SE, Gerlach JH, Cummings HJ, Zirngibl R, Greer PA, et al. Bipartite nuclear localization signals in the C terminus of human topoisomerase II alpha. Exp Cell Res 1997;237:452-5.

47. Mirski SE, Gerlach JH, Cole SP. Sequence determinants of nuclear localization in the alpha and beta isoforms of human topoisomerase II. Exp Cell Res 1999;251:329-39.

48. Kim D, Langmead B, Salzberg SL. HISAT: a fast spliced aligner with low memory requirements. Nat Methods 2015;12:357-60.

49. Robinson JT, Thorvaldsdottir H, Winckler W, Guttman M, Lander ES, et al. Integrative genomics viewer. Nat Biotechnol 2011;29:24-6.

50. Harker WG, Slade DL, Dalton WS, Meltzer PS, Trent JM. Multidrug resistance in mitoxantrone-selected HL-60 leukemia cells in the absence of P-glycoprotein overexpression. Cancer Res 1989;49:4542-9.

51. Harker WG, Slade DL, Drake FH, Parr RL. Mitoxantrone resistance in HL-60 leukemia cells: reduced nuclear topoisomerase II catalytic activity and drug-induced DNA cleavage in association with reduced expression of the topoisomerase II beta isoform. Biochemistry 1991;30:9953-61.

52. Lane AB, Giménez-Abián JF, Clarke DJ. A novel chromatin tether domain controls topoisomerase II $\alpha$ dynamics and mitotic chromosome formation. J Cell Biol 2013;203:471-86.

53. Feldhoff PW, Mirski SE, Cole SP, Sullivan DM. Altered subcellular distribution of topoisomerase II alpha in a drug-resistant human small cell lung cancer cell line. Cancer Res 1994;54:756-62.

54. Mirski SE, Cole SP. Cytoplasmic localization of a mutant M(r) 160,000 topoisomerase II alpha is associated with the loss of putative 
bipartite nuclear localization signals in a drug-resistant human lung cancer cell line. Cancer Res 1995;55:2129-34.

55. Ritke MK, Yalowich JC. Altered gene expression in human leukemia K562 cells selected for resistance to etoposide. Biochem Pharmacol 1993;46:2007-20.

56. Ritke MK, Roberts D, Allan WP, Raymond J, Bergoltz VV, et al. Altered stability of etoposide-induced topoisomerase Il-DNA complexes in resistant human leukemia K562 cells. Br J Cancer 1994;69:687-97.

57. Zwelling LA, Hinds M, Chan D, Mayes J, Sie KL, et al. Characterization of an amsacrine-resistant line of human leukemia cells. Evidence for a drug-resistant form of topoisomerase II. J Biol Chem 1989;264:16411-20.

58. Christie M, Chang CW, Róna G, Smith KM, Stewart AG, et al. Structural biology and regulation of protein import into the nucleus. J Mol Biol 2016;428:2060-90.

59. Gardiner LP, Roper DI, Hammonds TR, Maxwell A. The N-terminal domain of human topoisomerase II alpha is a DNA-dependent ATPase. Biochemistry 1998;37:16997-7004.

60. Campbell S, Maxwell A. The ATP-operated clamp of human DNA topoisomerase II alpha: hyperstimulation of ATPase by "piggy-back" binding. J Mol Biol 2002;320:171-88.

61. Hu T, Sage H, Hsieh TS. ATPase domain of eukaryotic DNA topoisomerase II. Inhibition of ATPase activity by the anti-cancer drug bisdioxopiperazine and ATP/ADP-induced dimerization. J Biol Chem 2002;277:5944-51.

62. Austin CA, Lee KC, Swan RL, Khazeem MM, Manville CM, et al. TOP2B: the first thirty years. Int J Mol Sci 2018;19. E2765.

63. Cowell IG, Austin CA. Do transcription factories and TOP2B provide a recipe for chromosome translocations in therapy-related leukemia? Cell Cycle 2012;11:3143-4.

64. Cowell IG, Sondka Z, Smith K, Lee KC, Manville CM, et al. Model for MLL translocations in therapy-related leukemia involving topoisomerase II $\beta$-mediated DNA strand breaks and gene proximity. Proc Natl Acad Sci U S A 2012;109:8989-94. 